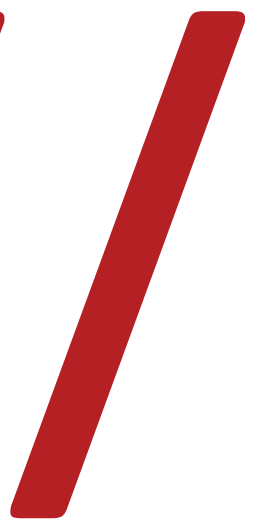

\title{
"Revolución Escritura":
} los ciné-tracts de JeanLuc Godard y el arte de mayo de 1968 "Revolution Writing": Jean-Luc Godard's cinétracts and the Art of May 1968

\section{Dominic Topp ${ }^{1}$}

\footnotetext{
${ }^{1}$ Profesor asociado en Cine en la Universidad de Kent, Reino Unido, donde enseña cursos de Historia del Cine, Arte y Cine, Cine Europeo de Posguerra, y Cognición y Emoción en Cine. En 2017 fue profesor invitado en la Facultad de Comunicaciones de la Pontificia Universidad Católica de Chile, donde enseñó un curso de Cine Clásico. Sus escritos sobre cine han aparecido en Studies in European Cinema y Alphaville: Journal of Film and Screen Media, y tiene capítulos en prensa sobre el maoísmo francés y las películas del Grupo Dziga Vertov, y el uso de revistas de fans para estudiar la percepción del público de directores del Hollywood clásico. Es miembro de la British Association of Film, Television and Screen Studies (BAFTSS) y el Aesthetics Research Group (ARC) de la Universidad de Kent. E-mail: djt29@kent.ac.uk
} 
Resumen: este artículo examina la participación de JeanLuc Godard en el proyecto ciné-tracts durante mayo y junio de 1968. Explora dos enfoques de la producción cultural que fueron prominentes en Francia en este periodo, y que influyeron en la práctica artística de Godard: uno utilitario y uno modernista. Luego, ofrece un análisis detallado de los ciné-tracts que produjo Godard, considerando cómo se articulan estas influencias tanto en sus materiales referenciales como en sus prácticas formales.

Palabras clave: Jean-Luc Godard; cine político; mayo de 1968.

Abstract: this article examines Jean-Luc Godard's involvement with the ciné-tracts project during May and June 1968. It explores two approaches to cultural production that were prominent in France in this period, and that influenced Godard's artistic practice: one utilitarian, the other modernist. It then offers a detailed analysis of the ciné-tracts that Godard produced, considering how these influences are manifested in both their referential materials and their formal practices.

Keywords: Jean-Luc Godard; political cinema; May 1968. 
A finales de la década de 1960, el aclamado director Jean-Luc Godard, insatisfecho con la interferencia del Estado francés bajo el gobierno del General Charles de Gaulle en el trabajo creativo, se alejó de la industria cinematográfica francesa. Cada vez más interesado en las tendencias antiautoritarias de la política de izquierda, comenzó a realizar películas que combinaban la política revolucionaria con la estética radical. Este artículo examina una etapa de la trayectoria de Godard en este período, su participación durante los eventos de mayo y junio de 1968 con el proyecto ciné-tracts. Esta era una iniciativa colectiva para hacer películas cortas, a ser proyectadas en reuniones políticas y actuar como una especie de noticiero alternativo a la información estatal.

En este artículo exploro primero dos enfoques muy diferentes de la producción cultural que fueron prominentes en Francia alrededor de mayo de 1968, y que influyeron en la práctica artística de Godard: uno utilitario y uno modernista. El enfoque utilitario, ejemplificado por los estudiantes de arte del Atelier Populaire, consideraba la función primaria del arte como la expresión de mensajes políticos claros, y alentaban la colaboración entre artistas y trabajadores. El enfoque modernista, ejemplificado por la revista literaria Tel Quel, consideraba la práctica estética experimental como una forma de compromiso político por su disrupción de la "transparencia" comunicativa asociada con la ideología burguesa. Luego, describo brevemente el proyecto ciné-tracts y las razones por las que le resultó atractivo a Godard, para posteriormente ofrecer un análisis detallado de sus ciné-tracts, considerando cómo estos articulan ambas influencias, la del enfoque utilitario y el modernista. Finalmente, ofrezco algunas reflexiones sobre de qué manera considerar en el análisis de la obra de Godard tales influencias podría afectar su estatus como autor, y cómo se desarrolló el enfoque de Godard sobre el cine político después de mayo de 1968.

\section{El enfoque utilitario: el Atelier Populaire}

En mayo y junio de 1968, un enfoque a la producción cultural que se centraba en una nueva relación entre el artista y la sociedad fue ofrecida por el Atelier Populaire, el taller de afiches creado por estudiantes de arte durante la ocupación de los estudios de la École des Beaux-Arts. Una de sus declaraciones definiendo su posición deja en claro su deseo de romper con la cultura establecida y la noción tradicional de artista:

Estamos contra del orden establecido de hoy. ¿Cuál es el orden establecido? Arte burgués y cultura burguesa. ¿Qué es la cultura burguesa? El medio por lo cual las fuerzas de opresión 
de la clase dominante aíslan y apartan a los artistas del resto de los trabajadores dándoles un estatus privilegiado. El privilegio encierra al artista en una prisión invisible. ("Atelier Populaire Oui Atelier Bourgeois Non”, 1968)

La concepción tradicional del arte como un ámbito autónomo de la autoexpresión individual se cuestionaba desde un análisis althusseriano de la cultura, considerada como: "una manifestación directa de la lucha de clases". En estos términos, la ilusión de que los artistas operan libres de la "realidad histórica" es una creación de la cultura burguesa que refuerza las estructuras de la sociedad capitalista, haciéndolas parecer naturales y aceptables.

Desde la perspectiva de los estudiantes del Atelier, el estatus privilegiado que disfrutan los artistas en la cultura burguesa los separaba del resto de la sociedad. Este aislamiento significa que incluso aquellos artistas que no estén de acuerdo con el sistema cultural tienen un rango limitado de opciones. O bien lo ignoran, realizando un aparente rechazo que es realmente una aceptación pasiva, o bien intentan desafiarlo mediante innovaciones formales que son fácilmente recuperadas por el mercado de arte comercial.

¿Cómo, entonces, pueden los artistas presuntamente radicales escapar de su “prisión invisible" a fin de proporcionar un desafío político real a la cultura burguesa? Primero, rechazando el sistema de escuelas de arte que la respalda, formando a los estudiantes para que acepten sus valores. Segundo, aliándose a los trabajadores en huelga para aprender de ellos. Esto significó, en la práctica, que los estudiantes proporcionaban las habilidades técnicas necesarias para producir los afiches mientras recurrían a los trabajadores para las ideas políticas que debían expresarse. Así, la producción cultural se convertiría en una actividad colectiva, además de un medio de reeducación política. Para el Atelier, el artista dejaba entonces de ser un especialista privilegiado, sino un trabajador más, que ayudaba a desarrollar "una cultura verdaderamente popular, es decir, del pueblo al servicio del pueblo" ("Atelier Populaire Oui Atelier Bourgeois Non", 1968).

Es importante subrayar que en este enfoque el arte está al servicio de la política. Esto se puede ver en el proceso por el cual se decidió qué afiches producir. El énfasis estaba en la comunicación efectiva, no en la innovación artística por sí misma, que podía oscurecer el mensaje político: "La experiencia nos ha enseñado el peligro de la ambigüedad y la necesidad de incorporar eslóganes como parte integral del diseño. La sinceridad, la fantasía y la imaginación solo son efectivas cuando interpretan y refuerzan el ataque hecho por el eslogan” (“Atelier Populaire Oui Atelier Bourgeois Non”, 1968). 
De hecho, los militantes del Atelier Populaire expresaban una profunda desconfianza hacia el arte modernista, que veían como una manifestación de la cultura burguesa, pues el mercado del arte premia la novedad como un bien de consumo, en tanto crea constantemente una demanda de innovación fresca. Además, el modernismo reproduce la división de clases sobre la que se construye el capitalismo mediante la creación de un arte elitista, que es dominio de expertos, "conocido por unos pocos y ajeno a las masas" "Essai de développement de: Atelier populaire: oui, Atelier bourgeois: non”, 1968). Lejos de amenazar la ideología estética dominante, la experimentación modernista simplemente refuerza el mito burgués de la libertad artística y la expresión individual, mientras distrae tanto a los artistas como a los consumidores de la realidad económica, política y social.

\section{El enfoque modernista: Tel Quel}

Una concepción muy diferente de lo que podría constituir una práctica artística radical fue ofrecida por los escritores asociados con la revista literaria experimental Tel Quel, que, desde su debut en 1960, había publicado obras de teóricos como Roland Barthes, Michel Foucault y Jacques Derrida, además de novelistas y poetas como Marcelin Pleynet, Denis Roche y su redactor jefe Philippe Sollers. Tel Quel respondió a la creciente politización de la vida intelectual francesa desarrollando una teoría materialista de la escritura que permitiera asociar la práctica artística modernista con la lucha de clases. Aunque partieron de algunas de las mismas suposiciones sobre la relación entre el arte y la sociedad de los estudiantes del Atelier Populaire, los escritores de Tel Quel llegaron a conclusiones que eran diametralmente opuestas a las suyas.

Mientras que el Atelier Populaire insistió en que las artes visuales en la sociedad capitalista funcionan como una herramienta para la transmisión y refuerzo de la ideología burguesa, Tel Quel encontró esta misma ideología manifestada en la forma literaria dominante, la novela, particularmente la novela realista tal como había sido desarrollada en el siglo XIX por escritores como Balzac. El realismo se criticó en dos niveles. Primero, se asumía que, al pretender ofrecer una representación transparente de la realidad, el realismo reforzaba el mito de la universalidad, es decir, la idea de que algo llamado "realidad" es directamente accesible, fuera de las particularidades del sistema social. Como dice Sollers (1966, p. 26):

la noción de realidad [es] en sí misma una convención y una conformidad, una especie de contrato tácito pasado entre el individuo y su grupo social: se declara real, en las circunstancias 
históricas dadas, lo que el número más grande a través del número en el poder, y por razones económicas específicas, está obligado a tomar por real.

De esta manera, el realismo sirve a la ideología dominante sugiriendo que el mundo en el que vivimos es inteligible y "legible", y que las relaciones sociales actuales son de alguna manera naturales, por lo tanto, fomentando la pasividad de los miembros de la sociedad. Mientras que el Atelier Populaire concibió el mundo del arte burgués como una prisión invisible, para Tel Quel la novela se comprendió como un tipo de cautiverio, en el que nuestras vidas se someten a roles preestablecidos, como si fuéramos personajes en una historia que ya se ha escrito: "LA NOVELA ES LA MANERA EN LA QUE ESTA SOCIEDAD SE HABLA, la manera en que el individuo DEBE VIVIRSE para ser aceptado allî” (SOLLERS, 1966, p. 21).

Segundo, se supuso que, así como el capitalismo opera enfatizando el valor de cambio de las mercancías sobre su valor de uso (y el trabajo que entra en su producción), el realismo encubre el trabajo de la producción literaria, promoviendo el significado sobre el significante. Así, según el filósofo Jean-Joseph Goux (1968, p. 83): "El trabajo (de escribir) y las modalidades del proceso de intercambio se desvanecen en la transparencia del sentido". Los lectores miran a través del texto para obtener acceso a una "verdad" preexistente que el texto pretende reflejar fielmente, mientras ignoran la realidad material de las palabras en la página y los códigos y convenciones literarios que el realismo trabaja para borrar. Por lo tanto, mientras el capitalismo florece enmascarando la explotación sobre la que se construye, el realismo literario lo legitima, al oscurecer el proceso de construcción mediante el cual se crea un texto. Es a partir de esta analogía entre un modo literario y un sistema socioeconómico que Sollers (1968, p. 22) puede afirmar “[1]a necesidad histórica de la conexión entre la práctica intelectual revolucionaria y la lucha del proletariado”.

Según esta lógica, el texto radical es uno que interrumpe y desfamiliariza el modo dominante de realismo, subrayando los procesos de escritura y lectura a través de los cuales se produce el significado. Esto se realiza por medio de un texto muy consciente de sí mismo, que juega con el lenguaje y la forma para evitar la mímesis, haciendo que el lector tome conciencia de lo antinatural, de lo que previamente parecía natural. Como había propuesto Barthes (1961, p. 40), “la obra más 'realista' no será la que 'pinte' la realidad, sino la que [...] explore lo más profundamente posible, la realidad irreal del lenguaje". Sólo produciendo textos que son "ilegibles" convencionalmente puede esa insistencia del realismo en la inteligibilidad ser 
desafiada y desmitificada, y la pasividad del lector ser reemplazada por una conciencia del texto como un sitio de contradicciones.

Así, el grupo Tel Quel intentó justificar su práctica literaria experimental en términos cuasi-marxistas, y reclamar para sus actividades una forma de compromiso político. Al hacerlo, tomaron una posición que era diametralmente opuesta a los estudiantes del Atelier Populaire, para quienes el papel del arte era servir al pueblo expresando mensajes políticos inequívocos, a los que se llegó a través de la discusión colectiva. Tel Quel defendió algo que se asemejaba al "arte del desafío", que el Atelier Populaire condenaba por mantener la división de clases, y propone lo "ilegible" donde el Atelier prioriza la comunicación clara.

\section{"Ciné-tractez!"}

A pesar de las diferencias considerables entre los enfoques utilitarista y modernista, ambas posiciones se articulan en los ciné-tracts que produjo Godard en mayo y junio de 1968. Los ciné-tracts fueron una iniciativa de Chris Marker para hacer cortos de $16 \mathrm{~mm}$ en blanco y negro que buscaban proyectarse en reuniones políticas como forma de "contrainformación" a las transmisiones de noticias de la agencia estatal de radio y televisión, la ORTF (Office de Radiodiffusion-Télévision Française). Un panfleto de la época explica la idea:

Qué es un ciné-tract?
Es 2 minutos y 44 segundos (es una bobina de 16 mm de
30 metros a 24 imágenes por segundo) de película muda
sobre un tema político, social o de otro tipo, dirigido a crear
debate y acción. jINTENTAMOS EXPRESAR NUESTROS
PENSAMIENTOS Y REACCIONES POR CINÉ-TRACTS!
¿Para qué?
Para: PROTESTAR - PROPONER - DESCARGAR -
INFORMAR - INTERROGAR - AFIRMAR -
CONVENCER - PENSAR - LLORAR - REÍR -
DENUNCIAR - CULTIVAR
(cit. En LAYERLE, 2008, p. 291)

Diseñado para ser realizado de forma rápida y económica, cada ciné-tract combinó fotos de los eventos de mayo y junio con intertítulos de leyendas y eslóganes. El ciné-tract se montaba en cámara para poder desarrollar la bobina y mostrarla casi de inmediato. Al igual que en los afiches del Atelier Populaire, se hizo hincapié en mensajes claros e inequívocos, expresados de manera legible y directa: "Comience por una idea simple, divídala en imágenes de acuerdo con el material disponible, 
[... y renuncie a los efectos demasiados ambiciosos. Reduzca el texto (intertítulos atractivos que sean bien legibles, como en la época del cine mudo) a lo esencial: lo más conciso, lo más claro, lo más llamativo" (cit. en LAYERLE, 2008, p. 291).

Los comentarios de Godard sobre los ciné-tracts sugieren varias razones por las cuales le atrajeron. Primero, ofrecieron una forma de hacer películas baratas que eludía la economía prohibitiva de la industria cinematográfica: "era una forma simple y barata de hacer cine político, para una rama sindical o un comité de acción, ya que la bobina cuesta un total de 50 francos" (FARGIER y SIZAIRE, 1969, p. 332). Los ciné-tracts proporcionaron una forma de cine amateur, que estaba libre de las restricciones comerciales del mercado y, por lo tanto, de las limitaciones estéticas que implicaban.

Segundo, los ciné-tracts fueron concebidos como un medio para proporcionar noticias sobre eventos que de otro modo no estarían disponibles: "Comenzaron con cosas sobre la policía, sobre la represión, en un intento de publicitar lo que estaba sucediendo. Los periódicos estaban reprimiendo mucho" ("Die Kunst ist eine Idee der Kapitalisten”, 1969). En particular, ofrecieron una alternativa a los medios estatales: "Había que proporcionar un servicio de noticias: mostrar imágenes y palabras que no se mostraban. Hacerlos es parte de la resistencia a las noticias gaullistas" (FARGIER y SIZAIRE, 1969, p. 332). La cobertura informativa de los eventos por las noticias oficiales fue extremadamente unilateral, lo que llevó a muchos periodistas y técnicos de la ORTF a ir a la huelga, exigiendo una mayor independencia. Los ciné-tracts - que se centran en temas como la brutalidad policial contra los manifestantes, la solidaridad de los manifestantes en las barricadas, las ocupaciones de las fábricas y las demandas de los trabajadores - se opusieron a la censura gubernamental y funcionaron como una especie de medio de comunicación alternativo.

Ahora bien, el atractivo más importante de los ciné-tracts para Godard, al parecer, fue que animaron la colaboración y el debate entre quienes los crearon: "el interés es menos exponerlos que hacerlos. Hay un interés local en trabajar juntos y discutir cosas. Esto nos ayuda a progresar" (FARGIER y SIZAIRE, 1969, p. 332). Específicamente, Godard sugirió que podrían brindar una oportunidad para la colaboración entre los cineastas y los que están fuera de la industria cinematográfica:

Este estilo de construcción puede dejar en claro a las personas que hacen cine que tenemos que trabajar con las personas que no lo hacen, y dado que construirlos es extremadamente simple, las personas que no lo hacen comprenden que los problemas del cine son realmente simples y que son complicados solamente porque la situación política es complicada. Las películas deben 
ser hechas por grupos sobre una idea política. [...] Creo que las películas deben hacerse con quienes las miran. (FARGIER y SIZAIRE, 1969, p. 332)

Los comentarios de Godard sobre el proyecto ciné-tracts sugieren un deseo de sumergirse en el trabajo colaborativo que recuerda el enfoque utilitario al arte político del Atelier Populaire. Godard presenta los ciné-tracts como un modo para compartir ideas y conocimientos sobre la realización cinematográfica. Los ciné-tracts podían alentar a los no profesionales a pensar que el cine era más accesible de lo que se les había hecho creer, motivando así el desarrollo de una especie de cine amateur que podía ofrecer una alternativa a la industria comercial de la que Godard era tan crítico.

\section{“En nuestra ambición”}

A pesar de su simpatía con la postura del Atelier Populaire, los cortos realizados por Godard nunca renunciaron completamente a su identidad artística individual, de corte modernista. De hecho, si bien ninguno de los ciné-tracts llevan los nombres de sus creadores, es fácil reconocer aquellos por los cuales fue responsable Godard. La señal más evidente de su participación es en el título inicial de cada película, el cual lleva el nombre "film tract" seguido de un número, escrito con la letra de Godard sobre la caja de la cinta de 16 mm Eastman en la que se filmó. Además, muchas de sus preocupaciones temáticas y estilísticas son altamente personales.

Los film tracts ${ }^{2}$ abordan, por una parte, temas que eran comunes en otras representaciones de los eventos de mayo de 1968. Tomemos, por ejemplo, el tema de los diferentes grupos sociales forjando vínculos e intercambiando ideas, cuya manifestación más frecuente fue el llamado a establecer una alianza entre estudiantes y trabajadores. Esto se expresa sucintamente en la película Film tract 16, en el que los eslóganes "Los estudiantes en la fábrica, los trabajadores en la universidad" y "Los estudiantes solidarios con los trabajadores" se yuxtaponen con fotos de ocupaciones estudiantiles y trabajadores en huelga en las puertas de una fábrica.

Otro tema en común con el arte de mayo es la violencia de la policía antidisturbios de las CRS (Compagnies républicaines de sécurité). Las fotos de las CRS que golpean a los manifestantes aparecen con frecuencia en los film tracts, junto con otras que muestran las lesiones sufridas. Las mismas imágenes a veces se reciclan

\footnotetext{
${ }^{2}$ De aquí en adelante utilizo el término film tracts para referirme a las películas que pueden adscribirse a Godard, y ciné-tracts para referirme a otras películas, o al proyecto en general.
} 
de una película a otra, no sólo entre los propios film tracts de Godard, sino también ciné-tracts en los que no trabajó. Si bien esto sugiere la cantidad limitada de imágenes que estaban disponibles, también da alguna indicación de una práctica en la que los cineastas compartían recursos entre sí.

Sin embargo, otros film tracts indican preocupaciones mucho más personales. Varios de ellos continúan ataques previos de Godard contra la cultura burguesa. Film tract 10, por ejemplo, muestra una foto de un soldado estadounidense herido en Vietnam, cuyos ojos han sido vendados. Esto se ve subvertido por el détournement de estilo situacionista: la frase "El imperialismo económico y cultural golpea ciegamente y permanece sordo al clamor del pueblo” se escribe sobre la foto, con una esvástica en un ojo y una cruz de Lorena en el otro, los dos símbolos unidos por un signo igual. La cruz de Lorena había sido adoptada por los franceses libres durante la Segunda Guerra Mundial en oposición a la esvástica, pero en la década de 1960 fue visto como símbolo del gaullismo. Así, una ecuación se establece entre el régimen de De Gaulle y el fascismo alemán, ambos vinculados al imperialismo estadounidense en Vietnam. Otra imagen en la misma película subvierte un anuncio de cigarrillos estadounidenses agregando el eslogan "Publicidad + Sexo = Fascismo", y Film tract 15 sugiere una analogía entre pornografía y cultura "oficial" yuxtaponiendo la frase "Mira las cosas a la cara toda tu vida si no quieres ser sodomizado por la cultura burguesa", con fotos de mujeres desnudas.

Los ataques de Godard contra la cultura burguesa se complementan con imágenes que representan la cultura revolucionaria. Film tract 10 incluye una foto del escritor Philippe Sollers con las palabras "Revolución Escritura" escritas sobre su rostro, y la frase "El libro en huelga asegura la información". Por otras partes, imágenes de Bertolt Brecht (Film tract 12) y de Vladimir Mayakovsky (Film tract 40) sugieren un vínculo entre la práctica de Godard y la obra de artistas marxistas anteriores.

Las referencias culturales de Godard también incluyen películas. A veces, una imagen de película se utiliza para ilustrar una palabra o frase que aparece como parte de un eslogan más largo. En Film tract 12, por ejemplo, la palabra "sociedad" se escribe sobre una foto de dos prostitutas con un cliente de Belle de jour (Bella de día, 1967) de Luis Buñuel, que repite la asociación godardiana entre la Francia moderna y la prostitución. En Film tract 40, las palabras "de la lucha" se ilustran por una foto de Torn Curtain (Cortina rasgada, 1966), de Alfred Hitchcock, que muestra a Paul Newman forcejeando con un adversario. Es difícil evitar ver asociaciones personales cuando al final de Film tract 9 las palabras "filosofía burguesa" se ilustran por una foto de revista de François Truffaut en el set de su película La mariée était en noir 
(La novia vestía de negro, 1968), con el titular "Hollywood sur Seine". La implicación es que Truffaut es un cineasta reaccionario, que por la lógica de Godard es convertido en un títere de la burguesía.

Godard también incluye imágenes de sus propias películas. Estos se sobrescriben con palabras y frases que sugieren el impulso y la vitalidad del proyecto político y cinematográfico radical combinado. En Film tract 12 una foto de Anne Wiazemsky en La Chinoise (1967) lleva la palabra "debe", mientras que una de Juliet Berto se inscribe "la juventud". En Film tract 23, las palabras "en nuestra ambición" se escriben sobre fotos de Wiazemsky y Jean-Pierre Léaud en La Chinoise. Y en Film tract 40 una foto de Léaud y Chantal Goya en Masculin féminin (Masculino femenino, 1966) se titula "revolucionarias".

Así como Godard se refiere a Brecht y Mayakovsky para invocar una tradición de cultura marxista radical, también cita a Serguéi Eisenstein varias veces como modelo de cine políticamente correcto. Imágenes de Stachka (La huelga, 1925), ¿Que viva México! (1931-1932) y Bezhin lug (El prado de Bezhin, 1937) aparecen en Film tract 12. En Film tract 40 se coloca una foto de una revolucionaria femenina de Oktyabr' (Octubre, 1928) junto a una de Bulle Ogier en L'Amour fou (1969) de Jacques Rivette, y las palabras "las conectando" se añadieron, sugiriendo que Rivette, uno de los pocos cineastas franceses cuyo trabajo Godard no consideraba como reaccionario en esta etapa, continúa el legado del cine de Eisenstein.

A pesar de su interés declarado en desarrollar un enfoque colaborativo más igualitario para el cine, Godard todavía no estaba listo para abandonar su identidad como autor. Encontraremos a continuación un balance similar entre los enfoques utilitarista y modernista al analizar los procedimientos formales mediante los cuales Godard organiza su material referencial. Como en el enfoque modernista de Tel Quel, a veces un juego estilístico (aquí entre imágenes y palabras) pone en riesgo la claridad de sus mensajes. Al mismo tiempo, sin embargo, Godard nunca rechaza completamente el sentido y mantiene algo de la claridad a la que aspiraba el Atelier Populaire, conservando cierta "legibilidad", a pesar de su experimentación formal.

\section{"Revolución escritura"}

Así describió Godard su método de trabajo para los film tracts: "Tomas una fotografía y una afirmación de alguien como Lenin o el Che y luego divides la frase del Che en, digamos, diez partes, una palabra por imagen, y agregas la foto que corresponde al significado, que 'corresponde' con él, o va en contra de él, dependiendo de las circunstancias" ("Die Kunst ist eine Idee der Kapitalisten”, 1969). De los once 
film tracts que han sobrevivido, nueve corresponden a esta descripción. De estos, seis (nos. 7, 8, 9, 13, 14 y 16) se estructuran en torno a un patrón simple ABAB: un eslogan político se divide en fragmentos (palabras individuales o frases cortas) y se distribuye a través de una serie de intertítulos, que se alternan con una variedad de imágenes fijas. En Film tract 8, por ejemplo, un eslogan maoísta, "Los trabajadores han tomado la bandera roja de la lucha de las manos frágiles de los estudiantes", se divide en seis intertítulos, que se alternan con fotos de los eventos de mayo (Figura 1):

1. Imagen: trabajadores detrás de una valla de fábrica

2. Título: los trabajadores

3. Imagen: trabajador frente a un fuego

4. Título: los trabajadores han tomado

5. Imagen: silueta de figuras con bandera en barricadas

6. Título: la bandera roja

7. Imagen: foto de un grupo de manifestantes con bandera, con el título COMPAÑEROS

8. Título: de la lucha

9. Imagen: demostrador lesionado llevado en camilla

10. Título: de las manos frágiles

11. Imagen: demostrador lesionado llevado a una ambulancia

12. Título: de las manos frágiles de los estudiantes
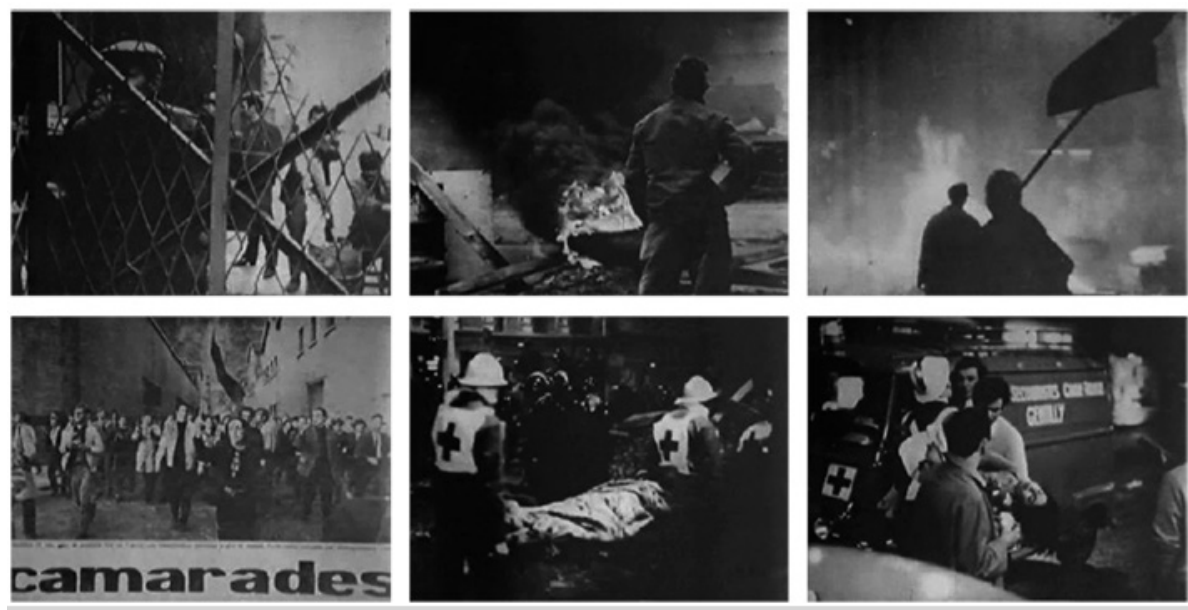

Figura 1: Film tract 8 (1968)

Estas dos categorías de plano entran en conflicto a la vez que se complementan. En un nivel, las imágenes se perciben como la interrupción del mensaje verbal, pero al mismo tiempo hay una asociación temática bastante clara entre cada imagen y las palabras que siguen. Las dos primeras imágenes muestran la ocupación de las fábricas por parte de los trabajadores, las dos segundas presentan banderas ondeadas en un 
desafío antiautoritario, y las dos últimas representan la fragilidad de la causa estudiantil, resaltando las lesiones sufridas por los manifestantes estudiantiles en las barricadas.

Mientras que Film tract 8 crea una correspondencia entre imágenes y palabras, en otra parte Godard usa imágenes que van “en contra” del significado del texto. En Film tract 7, fotos de la violencia de las CRS contra manifestantes se montan en paralelo con una cita ligeramente modificada del general De Gaulle, hecha en una entrevista de televisión en el período previo a las elecciones de fines de junio: "hay / una / solución / es / la participación / que cambia la condición del hombre / en medio de / la civilización moderna”. Aquí la disparidad entre las palabras conciliatorias de De Gaulle y la brutalidad mostrada en las imágenes de las CRS golpeando a manifestantes desarmados subvierte la declaración del general. Yuxtaponiendo las acciones de la policía antidisturbios con la "línea oficial" de De Gaulle, Godard sugiere el fascismo latente del Estado francés y ofrece una forma de resistencia al control gubernamental de los canales de medios oficiales mediante la contrainformación, que era uno de los objetivos del proyecto ciné-tracts.

La asociación entre palabras e imágenes no siempre es tan evidente. Film tract 9 , por ejemplo, se basa en una cita de Fidel Castro, parte de la cual se presenta de la siguiente manera:

\section{Título: $y a$}

2. Imagen: barricadas por la noche

3. Título: no aceptamos

4. Imagen: calle del Barrio Latino por la

5. Título: ningún tipo de

6. Imagen: CRS apuntando rifles en el aire

7. Título: ningún tipo de verdad evidente

8. Imagen: CRS golpeando con porras un manifestante en el suelo

La simplicidad y la prominencia del patrón de alternancia rítmica de imágenes e intertítulos hace que el espectador pueda registrarlo mientras, simultáneamente, percibe y procesa el mensaje textual. Se pueden entender algunas correspondencias generales, si bien la relación entre las imágenes y el texto es menos precisa. El "nosotros" del "no aceptamos" puede ser asociado con los manifestantes vislumbrados en las dos primeras fotos, y las fuerzas del orden gaullistas pueden ser vinculadas a la "verdad evidente" que ya no se acepta. Esta hipótesis está respaldada por una frase posterior: "Las verdades evidentes pertenecen a la filosofía burguesa." 
En este caso, es el estricto dualismo político de Godard lo que permite al espectador hacer asociaciones generales, incluso en ausencia de las pistas más específicas que se encuentran en Film tract 8. Las fuerzas de la revolución se oponen al Estado gaullista represivo, y cada referencia a una de las facciones puede equiparse rápidamente a todas las demás. Con la gama limitada de iconografía de la que se sirve Godard, el espectador puede encajar cada imagen sucesiva en su conjunto apropiado: estudiantes que protestan y trabajadores en huelga = bien; policía antidisturbios y ministros del gobierno = mal. De esta manera, los binarios políticos de los film tracts se parecen a la "estructura moral maniquea" que Murray Smith encuentra en las películas agitadoras soviéticas, como Stachka de Eisenstein y Arsenal de Alexander Dovzhenko (1929), donde un sistema redundante de claros valores políticos facilita la experimentación estilística sin riesgo de ambigüedad semántica (SMITH, 1995, pp. 197-204). Como señala Smith respecto a los cineastas soviéticos, las citas de Godard a "intertextos doctrinales" (Mao, Castro y el Che) también ayudan a reforzar la estabilidad de los mensajes de las películas. Dado que estaban destinadas a mostrarse en reuniones políticas, Godard suponía que al menos parte de su público reconocería las citas utilizadas, y que los espectadores simpatizarían generalmente de antemano con los valores afirmados. Por esta razón, no realiza ningún intento de convencer al espectador, su posición se da por sentada.

Ya hemos visto cómo Godard usa la sobre-inscripción para asociar elementos dentro de un solo plano. Cuando aparece una foto de Sollers con "Revolución Escritura" sobre su rostro, por ejemplo, se invita al espectador a vincular las palabras con la imagen. En dos de los film tracts (nos. 10 y 15), Godard aplica esta técnica a una variedad de imágenes, con cada plano independiente del resto. Pero en otros tres (nos. 12, 23 y 40), combina la sobre-inscripción con la distribución de un eslogan político a través de una serie de planos. Ahora los fragmentos de texto se escriben directamente sobre una serie de imágenes. Film tract 12, basado en una cita del Che, muestra cómo se puede construir una red de asociaciones entre imágenes y palabras en una serie de planos. (Figura 2): ${ }^{3}$

\footnotetext{
${ }_{3}^{3}$ Mi descripción de esta secuencia ignora dos juegos de palabras en los intertítulos de un tipo que analizo a continuación.
} 
Imagen

1. Foto de Juliet Berto en La Chinoise

2. Prisionero vietnamita con los ojos vendados y amordazado

3. Mujer desnuda que reclina

4. Ocupación estudiantil de una universidad

5. Foto de ¡Qué viva México!

6. Trabajadores en huelga en la puerta de una nuestra fábrica

7. Mano escribiendo en papel
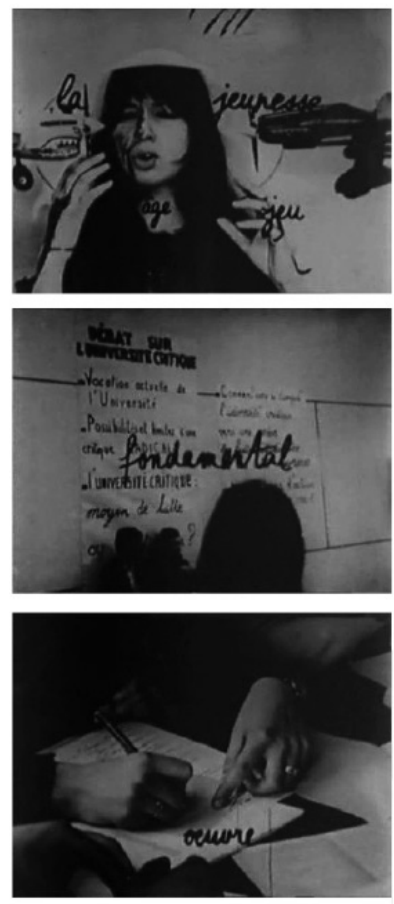

Texto

la juventud

es

la arcilla

fundamental

de

obra
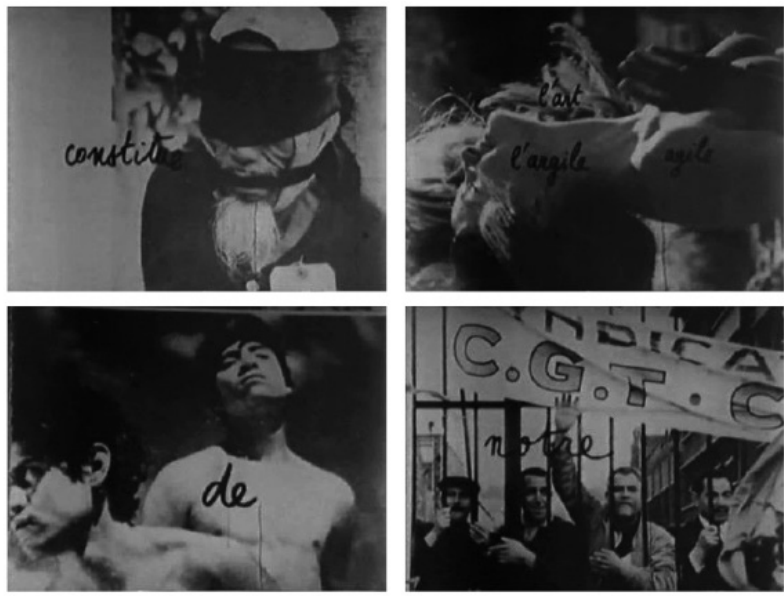

Figura 2: Film tract 12 (1968)

La mayoría de estas imágenes pueden ser vinculadas al tema del texto de la juventud: la joven maoísta en el primer plano, la joven en el plano 3, la universidad en el plano 4, los dos chicos mexicanos en el plano 5, la mano que escribe (probablemente un alumno) en el plano 7. Al igual que en otros lugares, la imagen de una ocupación de fábrica en el plano 6 agrega legitimidad a la causa de los estudiantes, relacionándola con la huelga de los trabajadores. Sin embargo, un tema adicional surge de la inclusión de varias imágenes de represión. La imagen de Berto en La Chinoise, interpretando el papel de Vietnam y atacada por aviones estadounidenses, se conecta con el prisionero 
vietnamita en el plano 2, que a su vez se conecta con los jóvenes cautivos en el plano 5. Así, la rebelión estudiantil en Francia se asocia tanto a la causa de la clase obrera, como a las luchas revolucionarias del Tercer Mundo contra la opresión imperialista. En un pasaje como éste, las imágenes no ilustran simplemente el texto. Se crea una interacción dinámica entre lo verbal y lo visual, que sugiere nuevos significados que no están contenidos individualmente en ninguno de los dos.

En una secuencia como la anterior, puede surgir a veces una tensión entre el mensaje verbal y las asociaciones entre imágenes y palabras. Con un tiempo de procesamiento limitado disponible, algunos espectadores podrían enfocarse en el eslogan que se está construyendo y perder algunas de las asociaciones entre los contenidos verbales y visuales de los planos individuales. Además, un espectador podría enfocarse en cada plano como un elemento discreto y distraerse de la frase que se presenta en planos sucesivos, o en un caso extremo, simplemente percibir una variedad de imágenes y frases independientes.

Una tensión similar resulta del enfoque de Godard sobre la palabra escrita. En lugar de presentar los intertítulos "fácilmente legibles" que los creadores de los ciné-tracts fueron alentados a usar, sus film tracts manipulan el texto de varias maneras para introducir asociaciones conceptuales adicionales. Una de sus técnicas es colocar las palabras en la pantalla para crear nuevos significados. En Film tract 16 (Figura 3), por ejemplo, una referencia a los obreros (les ouvriers) se organiza en tres líneas. Esto resalta la palabra ouvre (abierta), que puede vincularse a las imágenes de los trabajadores en huelga, en las puertas de la fábrica, quienes aparecen antes y después del intertítulo. Otro intertítulo presenta las palabras pour lutter efficacement (para luchar eficazmente), a fin de resaltar fac (universidad), una asociación apropiada dado el tema general de la solidaridad entre trabajadores y estudiantes. Una de las tácticas favoritas de Godard es descubrir obscenidades en las palabras relacionadas con el gobierno. En la frase contre la culture, por ejemplo, las palabras con (imbécil) y cul (culo) son enfatizadas. Cuando esto es seguido por una foto del entonces Ministro de Cultura francés, André Malraux, puede inferirse un insulto a su persona.
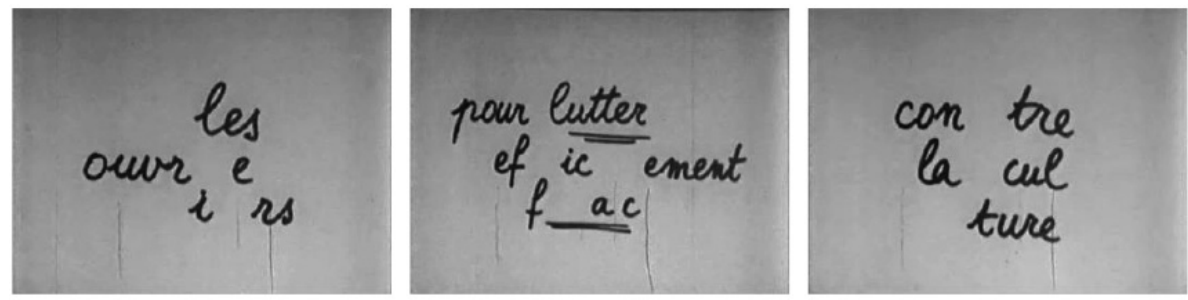

Figura: Film tract 16 (1968) 
Además de poner las palabras en la pantalla, Godard usa otras técnicas para resaltar palabras o letras. Film tract 14 monta en paralelo fotos de la policía antidisturbios con el eslogan "Las fuerzas del orden siempre tienen lazos de sangre con el desorden sexual” (Figura 4). Escribiendo con mayúscula la letra S cada vez que aparece (leS forceS de l'ordre ont toujourS deS lienS de Sang avec le déSordre Sexuel), Godard hace eco de la analogía entre las CRS y el SS Nazi.
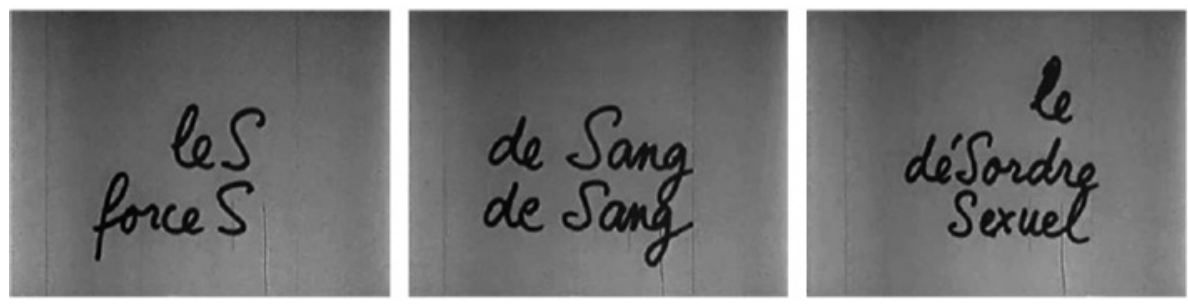

Figura 4: Film tract 14 (1968)

Juegos de palabras similares se combinan a veces con imágenes. En Film tract 23, la palabra ridicule (ridículo) se escribe sobre una foto de De Gaulle, y las letras se dividen para resaltar cul (culo), añadiendo un nuevo insulto. En Film tract 12 las letras de la palabra nous (nosotros) se disponen sobre una foto de soldados africanos para que se lea un mensaje antiimperialista en apoyo de la liberación del Tercer Mundo: no US (no EEUU) (Figura 5). Si bien los diversos juegos de palabras considerados hasta ahora ofrecen vínculos asociativos de un tipo u otro, a veces el diseño del texto parece ser puramente decorativo. Las palabras se multiplican, se dividen en varias líneas, o se organizan tanto horizontalmente como verticalmente, de una manera que puede restar legibilidad de un eslogan, especialmente con un tiempo de procesamiento limitado disponible (Figuras 6, 7).

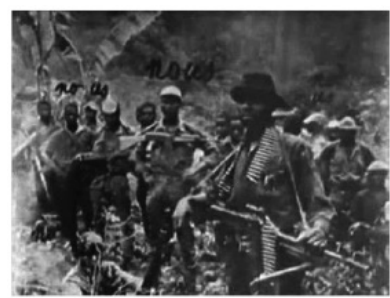

Figura 5: Film tract 12

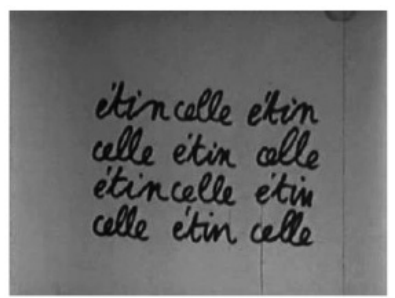

Figura 6: Film tract 13

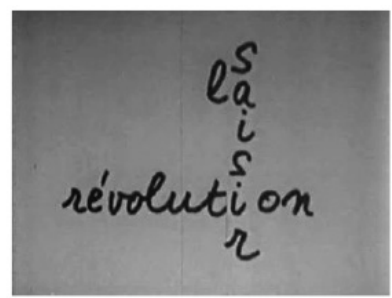

Figura 7: Film tract 8 
Como con la sobre-inscripción, cuanto más complicados son los contenidos de los planos individuales, mayor es el riesgo de que los espectadores pierdan el hilo del mensaje en su conjunto. Sin embargo, Godard hace concesiones a la función militante de las películas mediante varias técnicas para minimizar la posibilidad de sobrecarga cognitiva. Primero, como ya he mencionado, muchas de las imágenes utilizadas provienen de un rango relativamente pequeño de fotos que muestran eventos relacionados con mayo de 1968. Como resultado, la mayoría de ellas pueden ser relacionadas fácilmente con una de varias categorías generales (manifestantes estudiantiles, trabajadores en huelga, policía represiva), cada una de las cuales conlleva un conjunto de connotaciones extratextuales. Cuando se enfrenta a una imagen de un policía golpeando a un manifestante, por ejemplo, el espectador políticamente informado puede reconocer rápidamente que representa algo parecido a "la represión estatal del levantamiento popular", sin necesariamente tener que prestar atención a todos los detalles del evento. Esto minimiza el tiempo de procesamiento requerido, y significa que hay más tiempo disponible para contemplar las asociaciones entre imagen y texto.

Resulta claro, entonces, que Godard es consciente del riesgo de abrumar a los espectadores con los juegos de palabras y la sobre-inscripción a expensas de la eficiencia comunicativa. De hecho, algunos film tracts repiten partes de un eslogan una y otra vez, por esta razón. Consideremos, por ejemplo, este pasaje de Film tract 12, basado en otra cita del Che (Figura 8):

\section{Imagen}

1. Estudiantes en el patio de la Sorbona con un póster de Mao

2. Foto de Belle de jour

3. Dibujo de avión y pasajeros

4. Foto de Brecht

5. Estudiantes que marchan saludados por trabajadores

6. Foto de Anne Wiazemsky de La Chinoise

7. Imágenes de historieta de monjas

8. Collage del interior de una iglesia

9. Mujer desnuda

10. Alumnos en un laboratorio de idiomas

11. Página de un periódico maoísta
Texto

la

sociedad $\times 4$

en

su $\times 3$

conjunto $\mathrm{x} 2$

debe

convertirse

en

una

escuela $\times 3$

la sociedad en su conjunto debe convertirse en una escuela gigantesca 

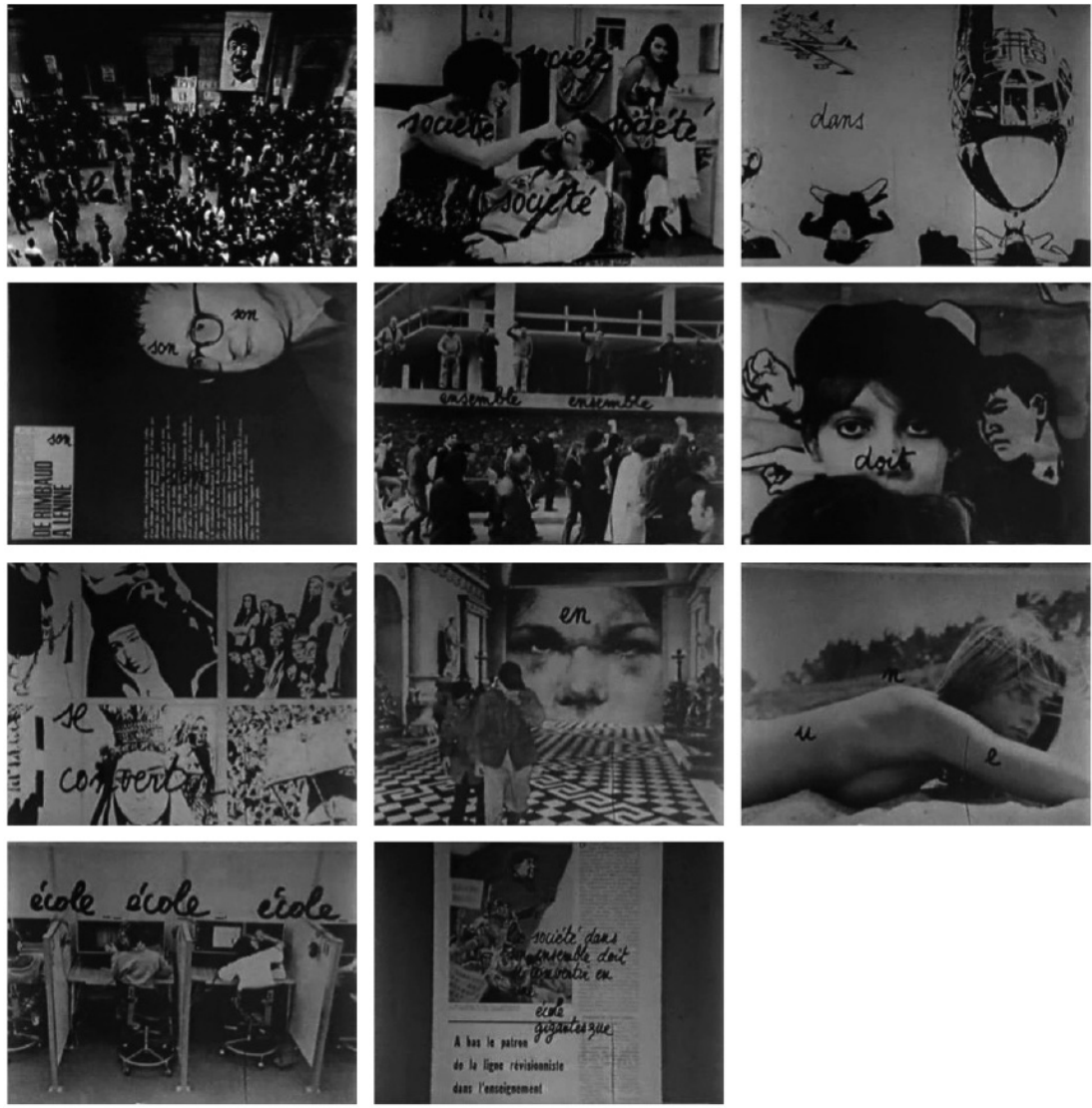

Figura 8: Film tract 12

Algunas de las asociaciones entre imagen y texto en este pasaje son relativamente fáciles de entender, como la correspondencia entre la palabra "escuela" y una foto de alumnos en el plano 10, o la palabra "conjunto" escrita sobre una imagen de trabajadores mostrando su solidaridad con los estudiantes en el plano 5. Es notable, además, el juego de palabras sobre la foto de una mujer desnuda en el plano 9, donde las letras que deletrean une (una) están dispuestas para que también puedan leerse como nue (desnuda). Sin embargo, en otros casos la relación entre imagen y texto es menos clara. ¿Cómo se conecta la palabra “su” con la foto de Brecht en el plano 4, por ejemplo? Sumado a ello, las imágenes utilizadas van más allá del "conjunto" de mayo de 1968, y algunas veces son bastante crípticas, por lo que requieren mayor atención del espectador, dejando menos espacio para procesar la frase. Para contrarrestar este efecto, el plano 11 proporciona una recapitulación de la frase completa, además de presentar 
su última palabra ("gigantesca”), que queda en la pantalla casi el doble de tiempo que cada uno de los diez planos anteriores (8 segundos en lugar de 4,5).

$\mathrm{Al}$ igual que con sus materiales referenciales, en el nivel formal Godard establece un equilibrio entre los enfoques utilitarista y modernista. Por un lado, utiliza técnicas experimentales que llaman la atención sobre la naturaleza construida del lenguaje (tanto cinemático como verbal). Por otro lado, los film tracts están lejos de rechazar el significado. Además de los eslóganes políticos que presentan, invitan a los espectadores a encontrar asociaciones conceptuales entre imágenes y palabras, y gran parte de su juego formal suscita la interpretación temática. Aunque en ocasiones los principios formales de las películas pueden entrar en conflicto entre sí, en la mayoría de los casos Godard es cuidadoso en gestionar su interacción para mantener la "legibilidad".

\section{Conclusiones}

Las películas de Godard de finales de la década de 1960 muestran una interacción dinámica entre un cineasta muy particular y un campo cultural que cambiaba rápidamente. Su trabajo de este período representó, tanto para críticos como para otros cineastas, un modelo influyente para la producción de un cine comprometido que pretendía "luchar en dos frentes", combinando temas políticos con una experimentación formal que podía ser entendida como una crítica ideológica a los modos dominantes de representación cinematográfica. Al mismo tiempo, Godard era sensible y receptivo a tendencias de la cultura francesa de su época. Su creciente politización se produjo junto a debates más amplios entre artistas e intelectuales sobre la política de la cultura y sobre aquello que constituía el arte comprometido políticamente. Esta "revolución cultural" se manifestó en una amplia variedad de formas, incluyendo dos enfoques significativamente diferentes sobre la producción cultural que influyeron particularmente en el cine de Godard de 1968, el utilitario y el modernista.

Si bien resaltar la relación entre las películas de Godard y el trabajo y las ideas de artistas literarios y visuales puede desafiar nuestra concepción sobre su condición de autor (un concepto a menudo indistinguible del mito romántico del genio creativo individual, no tocado por influencias), este artículo pretende mostrar que estudiar a un cineasta tan particular e idiosincrásico dentro de su contexto cultural puede ayudarnos a comprender y apreciar mejor su estética única. Que el cine de Godard recurra tanto al enfoque utilitario del Atelier Populaire como al enfoque modernista de Tel Quel, no significa que su trabajo se pueda reducir a ninguno de ellos. Uno de los logros de Godard en los film tracts es reunir dos estéticas que son teóricamente irreconciliables. Es la tensión entre estos dos enfoques la que crea la textura particular de la práctica 
cinematográfica de Godard, al tiempo que ofrece mensajes en apoyo a la causa de los trabajadores y los estudiantes, y opera como un interrogatorio modernista del proceso por el cual se producen estos mensajes. De hecho, podría decirse que la tensión presente en los film tracts representa, en parte, la realidad de los eventos de mayo de 1968, que difícilmente fueron el resultado de un movimiento unificado.

Sin embargo, al igual que en el ámbito político y cultural más amplio, el equilibrio entre los enfoques contradictorios que encontramos en los film tracts resultó difícil de mantener para Godard. Las películas que hizo en 1968 fueron recibidas con considerable hostilidad, y en 1969 el propio Godard condenó su trabajo anterior como "completamente reaccionario" (FARGIER y SIZAIRE, 1969, p. 335). Esta autocrítica lo llevaría a colaborar con Jean-Pierre Gorin bajo el lema del Grupo Dziga Vertov, en el que buscó nuevas formas de trabajar y un nuevo enfoque para "hacer políticamente las películas políticas".

\section{Referencias}

ANÓNIMO. Atelier populaire oui atelier bourgeois non. Paris, 21 mayo 1968.

ANÓNIMO. Essai de développement de: Atelier populaire: oui, Atelier bourgeois: non. Paris, 1968.

ANÓNIMO. Die Kunst ist eine Idee der Kapitalisten. Film, Hanover, v. 7, n. 4, p. 22-26, 1969.

BARTHES, R. La littérature, aujourd'hui. Tel Quel, Paris, n. 7, p. 32-41, 1961.

FARGIER, J. P. ; SIZAIRE, B. Deux heures avec Jean-Luc Godard. In: BERGALA, A. (Ed.). Jean-Luc Godard par Jean-Luc Godard: 1950-1984. Paris: Cahiers du cinéma, 1998. p. 332-335. tome 1

GOUX, J. J. Marx et l'inscription du travail. Tel Quel, Paris, n. 33, p. 77-94, 1968.

LAYERLE, S. Caméras en lutte en mai 68: par ailleurs le cinéma est une arme... Paris: Nouveau Monde, 2008.

SMITH, M. Engaging characters: fiction, emotion, and the cinema. Oxford: Oxford University Press, 1995.

SOLLERS, P. Le roman et l'expérience des limites. Tel Quel, Paris, n. 25, p. 20-34, 1966.

. La grande méthode. Tel Quel, Paris, n. 34, p. 21-27, 1968. 


\section{Referencias audiovisuales}

ARSENAL. Alexandr Dovzhenko, URSS, 1929.

BELLE de jour (Bella de día). Luis Buñuel, Francia, 1967.

BEZHIN lug (El prado de Bezhin). Serguéi Eisenstein, URSS, 1937.

FILM tract 7. Jean-Luc Godard, Francia, 1968.

FILM tract 8. Jean-Luc Godard, Francia, 1968.

FILM tract 9. Jean-Luc Godard, Francia, 1968.

FILM tract 10. Jean-Luc Godard, Francia, 1968.

FILM tract 12. Jean-Luc Godard, Francia, 1968.

FILM tract 13. Jean-Luc Godard, Francia, 1968.

FILM tract 14. Jean-Luc Godard, Francia, 1968.

FILM tract 15. Jean-Luc Godard, Francia, 1968.

FILM tract 16. Jean-Luc Godard, Francia, 1968.

FILM tract 23. Jean-Luc Godard, Francia, 1968.

FILM tract 40. Jean-Luc Godard, Francia, 1968.

LA CHINOISE. Jean-Luc Godard, Francia, 1967.

LA MARIÉE était en noir (La novia vestía de negro). François Truffaut, Francia, 1968.

L'AMOUR fou. Jacques Rivette, Francia, 1969.

MASCULIN féminin (Masculino femenino). Jean-Luc Godard, Francia, 1966.

OKTYABR' (Octubre). Serguéi Eisenstein, URSS, 1928.

¡QUE viva México! Serguéi Eisenstein, EEUU, 1930-1932.

STACHKA (La huelga). Serguéi Eisenstein, URSS, 1925.

TORN Curtain (Cortina rasgada). Alfred Hitchcock, EEUU, 1966.

submetido em: 22 dez. 2017 | aprovado em: 09 mar. 2018 